\title{
A IMPORTÂNCIA DA LEI 9.795/99 E DAS DIRETRIZES CURRICULARES NACIONAIS DA EDUCAÇÃO AMBIENTAL PARA DOCENTES
}

\author{
Berenice Gehlen Adams \\ Pedagoga Empresarial e Orientadora Educacional, pós graduada em Educação Ambiental, diretora da Apoema Cultura \\ Ambiental e coordenadora do Projeto Apoema - Educação Ambiental (www.apoema.com.br), \\ e-mail: bere@apoema.com.br. (Apoema Cultura Ambiental, http://www.apoema.com.br)
}

http://dx.doi.org/10.5902/223613086926

\section{RESUMO}

O artigo enfoca a importância da disseminação dos documentos que legitimam a Educação Ambiental, principalmente a LEI № 9.795/99 que institui a Educação Ambiental no Brasil - que é a base da resolução № 2, de 15 de junho de 2012, que estabelece as Diretrizes Curriculares Nacionais para a Educação Ambiental - para que docentes possam aprimorar suas práticas tornando a Educação Ambiental interdisciplinar, em todas as séries e em todas as disciplinas, bem como em todos os níveis de ensino, desde a Educação Infantil ao Ensino Superior. Aponta que há uma lacuna no que tange ao conhecimento dos professores desta importante Lei, bem como das diretrizes da EA recentemente aprovadas, e que sem o conhecimento destes documentos e de outros importantes documentos referência, a Educação Ambiental continuará a ser trabalhada de forma estanque, fragmentada, limitada a comemorações de datas como Dia da Água, Dia da Terra, Dia do Índio, Dia do Meio Ambiente, e limitada a temas como a separação de lixo, desastres ambientais e temáticas catastróficas, - que mais assustam do que educam - para o despertar de uma consciência ambiental. Sugere a promoção de um mini-curso para professores de diferentes níveis do ensino para vivenciarem estes importantes documentos que legitimam a Educação Ambiental no Brasil.

\section{ABSTRACT}

The article focuses on the importance of dissemination of documents that legitimize Environmental Education, especially Law No. 9.795/99 establishing the Environmental Education in Brazil - which is the basis of Resolution No. 2 of 15 June 2012 laying down guidelines National Curriculum for Environmental Education - so that teachers can improve its practices becoming interdisciplinary environmental education in all grades and in all subjects and at all levels of education, from kindergarten to college. It indicates that there is a gap regarding the teachers' knowledge of this important law and the guidelines recently approved EA, and without the knowledge of these documents and other important reference documents, Environmental Education will continue to be handled in a tight, fragmented, limited the dates of celebrations as World Water Day, Earth Day, Indian Day, Environment Day, and limited to issues such as waste separation, environmental disasters and catastrophic issues, - what more frightening than educate - to the awakening of environmental consciousness. Suggests the promotion of a mini-course for teachers of different educational levels to experience these important documents that legitimize Environmental Education in Brazil. 


\section{Apresentação}

O presente artigo aborda uma pesquisa bibliográfica referente à legitimação da Educação Ambiental (EA) no Brasil, faz algumas análises em relação ao seu conteúdo e em relação a sua importância para docentes da educação formal, e ressalta a necessidade de uma maior divulgação da Lei № 9.795/99, que institui a Política Nacional de Educação Ambiental em nosso país, bem como das Diretrizes Curriculares Nacionais para a Educação Ambiental. Não se pretende esgotar o assunto, uma vez que este alcança uma dimensão cada vez mais ampla, na medida em que se busca trazer à tona questões relevantes da legislação para a Educação Ambiental no Brasil. Pretende-se, sim, incentivar que todos os professores, em todas as escolas, de todos os níveis, tenham conhecimento da existência desta Lei da Educação Ambiental e suas diretrizes, do seu conteúdo, e de uma análise crítica sobre estes documentos para que possam auxiliar na perpetuação de ações que possibilitem a prática da EA de forma articulada, interdisciplinar e com uma abordagem crítica, voltada para o desenvolvimento de uma sociedade sustentável.

\section{Educação Ambiental como processo}

Entre várias definições sobre o que é EA, destaca-se que, para Medina (2001):

A Educação Ambiental como processo [...] consiste em propiciar às pessoas uma compreensão crítica e global do ambiente, para elucidar valores e desenvolver atitudes que Ihes permitam adotar uma posição consciente e participativa a respeito das questões relacionadas com a conservação e a adequada utilização dos recursos naturais deve ter como objetivos a melhoria da qualidade de vida e a eliminação da pobreza extrema e do consumismo desenfreado. (MEDINA, 2001, p.17).

Esta definição aborda a EA em sua amplitude: trata-se de um processo, e como processo não pode ser instalada como uma disciplina específica, mas deve estar implícita em todas ações educativas; trata-se de um processo que promove a compreensão crítica e global, dentro de uma visão sistêmica e não compartimentada ou fragmentada - por isso a interdisciplinaridade; trata-se de um processo que elucida valores buscando a alteridade, a equidade, estimulando a participação, promovendo a cidadania e a consciência ambiental.

Portanto, não se trata de uma tarefa fácil a de educar para a sustentabilidade ambiental, uma vez que a EA pretende estimular mudanças nos hábitos culturais, sociais e econômicos para alterar costumes que promovem o consumismo e priorizam o desenvolvimento econômico.

O enfoque interdisciplinar, presente na LEI № 9.795/99 é reforçado nas Diretrizes Curriculares Nacionais de Educação Ambiental:

Art. 8o - A Educação Ambiental, respeitando a autonomia da dinâmica escolar e acadêmica, deve ser desenvolvida como uma prática educativa integrada e interdisciplinar, contínua e permanente em todas as fases, etapas, níveis e modalidades, não devendo, como regra, ser implantada como disciplina ou componente curricular específico (BRASIL, 2012, p.70). 
A EA surgiu a partir da necessidade de mudanças de posturas humanas para com o ambiente, alardeada, principalmente, pelos movimentos ecológicos. Não cabe aqui levantar o histórico da EA, que se encontra à disposição em muitos artigos e livros, mas sim, fazer uma breve análise reflexiva em relação à legitimação que fundamenta esta prática, ou este processo educativo, a partir de levantamento bibliográfico.

\section{Educação Ambiental e o reconhecimento da sua legitimidade}

Em levantamento feito por Santos (2000) sobre como a EA era contemplada nas políticas públicas, este constatou que:

Em termos jurídicos propriamente dito, vemos que no Brasil o parágrafo 1ํ, VI, do art. 255 da Constituição Federal, determina ao Poder Público a promoção da EA em todos os níveis de ensino. Mas, apesar desta previsão constitucional, bem como o fato da EA já ser reconhecida mundialmente como ciência educacional e também recomendada pela UNESCO e a Agenda 21, pouco era feito no Brasil para a sua implantação concreta no ensino. O que existia era fruto dos esforços de alguns abnegados professores e educadores, não havendo a atenção que merece o tema pelo Poder Público e as entidades particulares de ensino (SANTOS, 2000, s/p.)

Portanto, percebe-se que foi preciso criar outras ferramentas jurídicas que possibilitassem o avanço desta prática. E foi com a publicação da Lei 9.795, de 27/4/99, que dispõe sobre a EA, e que institui a Política Nacional de Educação Ambiental e dá outras providências é que esta prática educativa ganhou mais força.

Sobre a LEI 9.795/99, Santos (idem) indica que:

a lei define juridicamente EA como "o processo por meio dos quais o indivíduo e a coletividade constroem valores sociais, conhecimentos, habilidades, atitudes e competências voltadas para a conservação do meio ambiente, bem de uso comum do povo, essencial à sadia qualidade de vida e sua sustentabilidade (art.1ㅇ) e Instituiu a Política Nacional do Meio Ambiente (art. 60) definindo seus objetivos fundamentais como por exemplo o desenvolvimento de uma compreensão integrada do meio ambiente em suas múltiplas e complexas relações, envolvendo aspectos ecológicos, psicológicos, legais, políticos, sociais, econômicos, científicos, culturais e éticos, bem como o incentivo à participação individual e coletivas, permanente e responsável, na preservação do equilíbrio do meio ambiente, entendendo-se a defesa da qualidade ambiental como o valor inseparável do exercício da cidadania (art.5으. Interessante na nova legislação é que reconheceu a EA como componente essencial e permanente da educação nacional, distinguindo juntamente com o seu caráter formal o caráter não-formal, ou seja a educação ambiental não oficial que já vinha sendo praticada por educadores, pessoas de várias áreas de atividades e mesmo entidades, obrigando ao poder público em todas as suas esferas incentivá-la (art. 3으 e 13으).

Outra tentativa de legitimar e reforçar a EA como prática interdisciplinar, explicitada na Lei 9.795/99 é a sua inclusão nos Parâmetros Curriculares Nacionais. Conforme Furtado (2009),

[...] a importância da Educação Ambiental se explicita formalmente na obrigatoriedade constitucional, em sua inclusão nos Parâmetros Curriculares Nacionais e na publicação da 
Lei Federal que define a Política Nacional de Educação Ambiental (Lei 9795 /1999), instrumentos legais e documentos governamentais que asseguram a temática um caráter transversal, indispensável e indissociável da política educacional brasileira (FURTADO, 2009, p.346).

Contudo, apesar destas iniciativas, ainda persiste a prática de uma EA que carece de maior compreensão quanto a sua aplicação interdisciplinar a ser inclusa no processo educacional vigente.

Uma nova tentativa de reforçar a legitimidade da EA surge recentemente com a homologação das Diretrizes Curriculares Nacionais da Educação Ambiental (BRASIL, 2012, p.70) indicando que "as Diretrizes Curriculares Nacionais para a Educação Básica em todas as suas etapas e modalidades reconhecem a relevância e a obrigatoriedade da Educação Ambiental".

Sendo, então, a EA legitimada e considerada como um componente essencial e permanente da educação nacional é fundamental que o corpo docente de todos os espaços de educação formal tenha acesso a esta lei e aos demais documentos que a legitimam. De outra forma, estes espaços de ensino não poderão ser coerentes com o que na lei está explícito, como por exemplo, instaurar uma disciplina específica de EA, o que contraria um dos seus importantes princípios apontados na lei e em outros importantes documentos que regem a EA, que é o da interdisciplinaridade.

\section{Os docentes e a Lei 9.795/99}

A EA como processo educativo voltado para a sustentabilidade ambiental tem diferentes abordagens e uma ampla gama de interpretações, e não se trata de uma novidade, uma vez que sua trajetória tem início tímido já a partir da década de 70. Medina - que tem ampla experiência em Educação Ambiental e é um ícone no rol de autores que tratam dessa temática compreende que "a Educação Ambiental é um campo de conhecimento em formação, permeado por contradições e com um histórico que lamentavelmente torna mais complexo o seu processo de assimilação". (MEDINA, 2001, p.17)

A realidade apontada por Medina, passados praticamente onze anos ainda pode ser considerada no contexto atual, que indica, por exemplo, o desconhecimento da Lei № 9.795 por parte de muitos professores, conforme mostram os resultados de uma pesquisa realizada, justificada com base na Lei № 9.795/99, que segue:

\footnotetext{
"A lei no 9.795/99, que regulamenta a educação ambiental, estabelece que a mesma deve ser trabalhada em caráter interdisciplinar em todos os níveis e modalidades de ensino de modo a formar sujeitos com conhecimentos, valores e habilidades com vistas ao manejo sustentável do meio ambiente. Entende-se, assim, ser importante verificar como tem sido trabalhada a temática ambiental nas escolas" (OLIVEIRA, 2009, s/p).
}

A referida pesquisa buscou verificar como está sendo aplicada a EA em algumas escolas selecionadas e concluiu, entre outros resultados não relevantes para esta temática, que "os professores não citam a lei de educação ambiental, contudo acreditam que a temática deva 
ser trabalhada nas aulas" (OLIVEIRA, 2009, s/p), o que revela que esta ferramenta importantíssima para a compreensão da EA não tem sido levada ao conhecimento dos docentes como deveria.

A pesquisa traz outro resultado que confirma a necessidade de divulgação para apropriação desta ferramenta pelo corpo docente para aprimorar e disseminar essa prática educacional, quando indica que "[...] a temática ambiental está presente tanto no trabalho dos professores como no material didático, mas não é trabalhada interdisciplinarmente como determina a legislação de educação ambiental" (OLIVEIRA, 2009, s/p).

Estas constatações revelam as causas da dificuldade de implementação da EA no sistema de ensino. Equivocadamente a EA é percebida como ensino da Ecologia, ou que deve ser tratada na disciplina de Ciências, justamente por falta de conhecimento de referenciais teóricos a cerca da EA. Conforme Medina (2001):

[...] a essas dificuldades acrescentam-se as formas muitas vezes simplistas com que tem sido concebida e aplicada a Educação Ambiental, reduzindo-a a processos de sensibilização ou percepção ambiental, geralmente orientados pela inserção de conteúdos da área biológica, ou a atividades pontuais no Dia do Meio Ambiente, do Índio, da Árvore, ou visitas a parques ou reservas. Não queremos negar a importância dessas atividades, apenas assinalar que elas são necessárias, mas não suficientes, para desenvolver conhecimentos e valores, tais como eles são postulados nos PCN de Meio Ambiente e de Ética. (MEDINA, 2001, p. 18)

Em pesquisa realizada por Oliveira (2009, s/p) pode-se confirmar o que Medina aponta: que a EA é tratada de forma pontual, sem que sejam feitas as importantes conexões das temáticas entre diferentes disciplinas. Sobre isto, destaca-se, então, que:

Em relação à abordagem da temática ambiental observou-se que, embora ela considere aspectos sociais da questão ambiental, ainda não se pode afirmar que se caracterize como uma abordagem socioambiental; tampouco se identificou uma educação ambiental crítica e emancipatória. (OLIVEIRA, 2009, s/p).

\section{Visão Antropocêntrica apontada na Lei 9.795/99}

Mesmo percebendo a importância da Lei 9795/99 para a implementação da EA, Furtado (2009) faz uma crítica a esta Lei, referente à visão antropocêntrica de meio ambiente, referindo-se a este como se este fosse um bem consumível, o que contraria os princípios da EA proclamados na Carta da Terra, e no Tratado de Educação Ambiental para Sociedades Sustentáveis e Responsabilidade Global, importantes documentos elaborados no Fórum das ONG's, evento paralelo a Eco 92 ou Rio 92.

No primeiro artigo da Lei 9795/99, a conservação do meio ambiente é associada ao "bem de uso comum do povo". No meu ponto de vista, a utilização dessa expressão remete diretamente a uma concepção antropocêntrica, pois faz relação de "uso" como bem jurídico de forma generalizada, não mencionando até que ponto podemos "utilizar" o ambiente sem prejudicá-lo ou agredi-lo. Além disso, não faz nenhuma referência ao tipo de impacto que uma grande empresa ou um cidadão comum podem causar no ambiente, 
demonstrando uma certa omissão em relação a responsabilidade que os grandes empresários possuem. (FURTADO, 2009, p.347).

Entende-se, portanto, que a Lei 9.795/99 é um importante documento para balizar as ações educativas que incluem o meio ambiente e suas relações em todas as disciplinas, mas que também pode ser objeto de estudo quanto ao que foi alertado por Furtado (2009) sobre a postura antropocêntrica que se refere ao meio ambiente como "um bem de uso comum do povo". Ao se trabalhar a referida Lei com professores, pode-se abordar essa questão do antropocentrismo, a fim de se promover uma reflexão aprofundada sobre enfoques que podem trazer algum tipo de contradição, aprimorando o senso crítico dos docentes.

\section{Os princípios e objetivos da Educação Ambiental}

O Capítulo I das Diretrizes Nacionais Curriculares da Educação Ambiental (BRASIL, 2012, p. 70) define os princípios que a norteiam a partir do que dispõe a Lei no 9.795, de 1999, são eles:

I - totalidade como categoria de análise fundamental em formação, análises, estudos e produção de conhecimento sobre o meio ambiente;

II - interdependência entre o meio natural, o socioeconômico e o cultural, sob o enfoque humanista, democrático e participativo;

III - pluralismo de ideias e concepções pedagógicas;

IV - vinculação entre ética, educação, trabalho e práticas sociais na garantia de continuidade dos estudos e da qualidade social da educação;

$\mathrm{V}$ - articulação na abordagem de uma perspectiva crítica e transformadora dos desafios ambientais a serem enfrentados pelas atuais e futuras gerações, nas dimensões locais, regionais, nacionais e globais;

VI - respeito à pluralidade e à diversidade, seja individual, seja coletiva, étnica, racial, social e cultural, disseminando os direitos de existência e permanência e o valor da multiculturalidade e plurietnicidade do país e do desenvolvimento da cidadania planetária.

Observando cada um dos princípios delimitados como norteadores das práticas de EA, podem-se destacar alguns conceitos chave como: totalidade, interdependência, pluralismo, ética, articulação, perspectiva crítica, respeito, direitos, multiculturalidade, plurietnicidade e cidadania planetária, conceitos estes que devem ser bem compreendidos pelo corpo docente para que seja possível alcançar os objetivos da EA, descritos nas Diretrizes, no Capítulo II, quais sejam:

I - desenvolver a compreensão integrada do meio ambiente em suas múltiplas e complexas relações para fomentar novas práticas sociais e de produção e consumo;

II - garantir a democratização e o acesso às informações referentes à área socioambiental;

III - estimular a mobilização social e política e o fortalecimento da consciência crítica sobre a dimensão socioambiental;

IV - incentivar a participação individual e coletiva, permanente e responsável, na preservação do equilíbrio do meio ambiente, entendendo-se a defesa da qualidade ambiental como um valor inseparável do exercício da cidadania; 


\begin{abstract}
V - estimular a cooperação entre as diversas regiões do País, em diferentes formas de arranjos territoriais, visando à construção de uma sociedade ambientalmente justa e sustentável;

VI - fomentar e fortalecer a integração entre ciência e tecnologia, visando à sustentabilidade socioambiental;

VII - fortalecer a cidadania, a autodeterminação dos povos e a solidariedade, a igualdade e o respeito aos direitos humanos, valendo-se de estratégias democráticas e da interação entre as culturas, como fundamentos para o futuro da humanidade;

VIII - promover o cuidado com a comunidade de vida, a integridade dos ecossistemas, a justiça econômica, a equidade social, étnica, racial e de gênero, e o diálogo para a convivência e a paz;

IX - promover os conhecimentos dos diversos grupos sociais formativos do País que utilizam e preservam a biodiversidade.
\end{abstract}

Os objetivos apresentados são amplos, abrangentes e remetem a uma educação voltada para o desenvolvimento do senso crítico em relação ao ambiente em que vivemos relacionando aspectos socioambientais e cidadania, evidenciando, assim, o caráter democrático que deve estar presente nas práticas de EA.

\title{
Disseminação dos documentos que legitimam a Educação Ambiental
}

A partir do exposto compreende-se que a EA é um processo de educação, e não uma disciplina, então, trata-se de uma prática pedagógica interdisciplinar, que deve ser desenvolvida em todos os níveis de ensino, desde a Educação Infantil ao Ensino Superior, nos mais diferentes contextos educacionais. Isto é o que está explícito nos principais documentos referência da EA, destacando-se a Lei № 9795/99, mas infelizmente poucos educadores os conhecem.

Nas Diretrizes Curriculares Nacionais da Educação Ambiental (BRASIL, 2012, p.71), especificamente o Art. 11, destaca que: "a dimensão socioambiental [...] deve constar dos currículos de formação inicial e continuada dos profissionais da educação, considerando a consciência e o respeito à diversidade multiétnica e multicultural do País", e destaca em Parágrafo único que: "os professores em atividade devem receber formação complementar em suas áreas de atuação, com o propósito de atender de forma pertinente ao cumprimento dos princípios e objetivos da Educação Ambiental".

Considera-se, portanto, ser fundamental elaborar um programa de capacitação ou mini-curso para equipes pedagógicas e equipes diretivas para que estas tenham não somente acesso aos documentos referência que balizam a EA, mas que também possam vivenciá-los através de atividades dinâmicas e de reflexão para o aprimoramento da práxis da Educação Ambiental, podendo, estes, tornarem-se multiplicadores.

Compreende-se ser fundamental que sejam muito bem esclarecidos aos professores os objetivos das Diretrizes Curriculares Nacionais da Educação Ambiental (BRASIL, 2012, p. 70) apresentados no Art. 1으, que são:

I - sistematizar os preceitos definidos na citada Lei [LEI 9.795/99], bem como os avanços que ocorreram na área para que contribuam com a formação humana de sujeitos 
concretos que vivem em determinado meio ambiente, contexto histórico e sociocultural, com suas condições físicas, emocionais, intelectuais, culturais;

II - estimular a reflexão crítica e propositiva da inserção da Educação Ambiental na formulação, execução e avaliação dos projetos institucionais e pedagógicos das instituições de ensino, para que a concepção de Educação Ambiental como integrante do currículo supere a mera distribuição do tema pelos demais componentes;

III - orientar os cursos de formação de docentes para a Educação Básica;

IV - orientar os sistemas educativos dos diferentes entes federados.

O primeiro objetivo citado deixa claro que a compreensão das Diretrizes Curriculares Nacionais da Educação Ambiental requer conhecimento prévio dos preceitos definidos na Lei 9.795/99. Também estabelece a importância de realização de um trabalho didático-pedagógico que vincule as atividades educacionais à realidade vivencial do educando em seu amplo contexto.

O segundo objetivo apresentado evidencia a importância do documento como recurso de reflexão para avaliação de como a EA está vinculada nas propostas pedagógicas e sua integração no currículo escolar.

Já os terceiro e quarto objetivos apontados indicam a utilização do documento como recurso pedagógico a ser trabalhado nos cursos de formação de docentes e na orientação de sistemas de ensino diversos.

Para que seja alcançado com êxito o primeiro objetivo fica claro que o trabalho de vivências com estes documentos deve se iniciar pela Lei que regulamenta a EA em nosso País.

Conforme o Art. 14, das Diretrizes Curriculares Nacionais da Educação Ambiental (2012, p. 71), a EA deve contemplar uma abordagem curricular que enfoque a natureza como fonte de vida e relacione ambiente e justiça social, associando a direitos humanos, saúde, trabalho, consumo, vinculados a pluralidade étnica, racial, de gênero, de diversidade sexual, e à superação do racismo, discriminação e injustiça social, salientando que:

\footnotetext{
II - abordagem curricular integrada e transversal, contínua e permanente em todas as áreas de conhecimento, componentes curriculares e atividades escolares e acadêmicas;

III - aprofundamento do pensamento crítico-reflexivo mediante estudos científicos, socioeconômicos, políticos e históricos a partir da dimensão socioambiental, valorizando a participação, a cooperação, o senso de justiça e a responsabilidade da comunidade educacional em contraposição às relações de dominação e exploração presentes na realidade atual;

IV - incentivo à pesquisa e à apropriação de instrumentos pedagógicos e metodológicos que aprimorem a prática discente e docente e a cidadania ambiental;

V - estímulo à constituição de instituições de ensino como espaços educadores sustentáveis, integrando proposta curricular, gestão democrática, edificações, tornando-as referências de sustentabilidade socioambiental.
}

Senso assim compreende-se que o currículo deverá "abraçar" a temática ambiental de forma que ela esteja permanentemente vinculada às atividades rotineiras dos sistemas de ensino (escolares e acadêmicos) para promover nos educandos o desenvolvimento crítico e reflexivo de tudo o que envolve a vida em sociedade, incentivando a participação pela cooperação responsável, sempre com justiça. $O$ incentivo à pesquisa e a transformação dos espaços escolares 
tornando-os sustentáveis também são abordagens que devem estar presentes na inserção da EA ao currículo.

Uma série de atividades, a partir do exposto, pode ser desenvolvida com equipes pedagógicas e/ou professores, em momentos de reuniões. A apresentação deste artigo, por exemplo, poderá ser um incentivo para que professores tenham interesse nestes documentos.

A seguir, apresentam-se algumas sugestões que podem servir como ponto de partida para a efetivação de atividades em reuniões pedagógicas, que promovam o "empoderamento" dos princípios e dos objetivos da EA por parte dos professores, com base nos documentos que legitimam a EA no Brasil:

- Apresentar a Lei № 9795/99 de forma impressa para leitura prévia do documento. prévia do documento.

- Apresentar das Diretrizes Curriculares Nacionais de Educação Ambiental para leitura

- Realizar atividades em grupos para promoção de debates sobre os documentos levantando questões a serem respondidas, podendo cada grupo se encarregar de uma parte dos documentos, por exemplo, ao trabalhar a LEI 9.795/99 pode-se dividir a equipe de professores em dois grupos. Cada grupo fica encarregado de uma parte do documento. Ambos os grupos formulam três perguntas que, após um tempo determinado, serão respondidas e debatidas. Esta dinâmica promove interação e debate sobre conceitos presentes nos documentos.

- Destacar conceitos chaves como: interdisciplinaridade, dimensão socioambiental, preservação, biodiversidade, consumo, reciclagem, cidadania, entre outros, e propor atividades dinâmicas e de pesquisa para sua exploração e promoção de debates sobre os mesmos fazendo associações à EA.

- Elaborar painéis utilizando diferentes técnicas destacando os objetivos da EA explicitados nos documentos.

escolha.

- Destacar parágrafos que considerem relevantes nos documentos e justificar a

- Fazer associações da prática educativa em relação aos documentos.

- Elaborar planejamento de unidades de estudo sobre um determinado assunto que seja relevante para a realidade ambiental escolar evidenciando consonância com os objetivos e princípios da EA apresentados nos documentos.

- Promover palestras aos professores e equipe diretiva com Especialistas em EA.

Estas são apenas algumas sugestões de como estes documentos podem ser trabalhados em um mini-curso com o corpo docente de espaços educacionais, de forma que promovam vivências e estudos sobre os mesmos, pois muitas vezes, somente distribuindo o documento para leitura dos professores, estes não absorvem o conteúdo explicitado, e na troca 
de ideias, vivências e experiências em grupos há uma compreensão maior dos conteúdos dos mesmos, o que certamente promoverá o aprimoramento da práxis da Educação Ambiental.

\section{REFERÊNCIAS BIBLIOGRÁFICAS}

BRASIL. RESOLUÇÃO № 2, DE 15 DE JUNHO DE 2012, que estabelece as Diretrizes Curriculares Nacionais para a Educação Ambiental. DOU № 116, Seção 1, págs. 70-71 de $18 / 06 / 2012$.

. Lei n. 9795 - 27 de abril de 1999. Dispõe sobre a educação ambiental. Política Nacional de Educação Ambiental. Brasília, 1999.

- Ministério da Educação. Secretaria de Educação Média e Tecnológica.

Parâmetros Curriculares Nacionais. Brasília, 1999.

FURTADO, D. J. Os caminhos da educação ambiental nos espaços formais de ensinoaprendizagem: qual o papel da política nacional de Educação Ambiental? Rev. eletrônica Mestr. Educ. Ambient. ISSN 1517-1256, v. 22, janeiro a julho de 2009. Disponivel em/ <http://www.remea.furg.br/edicoes/vol22/art24v22.pdf> Acesso em: 20/10.09.

MEDINA, N. M. A formação dos professores em Educação Ambiental. In: Panorama da educação ambiental no ensino fundamental / Secretaria de Educação Fundamental - Brasília : MEC ; SEF, 2001.

OLIVEIRA, M. E. de, A Temática Ambiental no Ensino Médio.<http://www.educacao.ufpr.br/publicacoes/sedpeef/resumos_comunicacao_\%20oral_\%20 em_\%20pdf/mariaeunice.pdf> Acesso em 20/10/2009

SANTOS, A. S. R dos, Educação ambiental e o poder público. 2000. Disponível em < http://www.aultimaarcadenoe.com.br/educacao-ambiental/> Acesso em 16/10/09 